\title{
Os riscos climáticos no circuito da notícia da Gazeta do Povo
}

Eloisa Beling Loose

\section{Resumo}

0 artigo compreende 0 estudo entre comunicação e percepção a respeito das mudanças climáticas e seus riscos no âmbito do circuito da notícia de um jornal local. Para tanto, a pesquisa analisa a Gazeta do Povo e os atores que participaram de sua produção (fontes de informação e jornalistas) e recepção (leitores). Foram feitas observação participante das rotinas dos jornalistas, análises de percepção de risco dos vários atores sociais e de enquadramentos das notícias com o objetivo de triangular os resultados a partir da hermenêutica de profundidade. Dentre os achados, constata-se que a percepção de risco climático está distante dos leitores, o que revela que a mediação jornalística amplificou os efeitos negativos globais e a discussão sobre acordos internacionais.

\section{Palavras-Chave}

Mudanças climáticas. Circuito da notícia. Percepção de risco.

\section{Eloisa Beling Loose I eloisa.beling@gmail.com}

Pós-doutoranda do Programa de Pós-Graduação em Comunicação e Informação da Universidade Federal do Rio Grande do Sul UFRGS, Brasil, com bolsa Capes. Doutora em Meio Ambiente e Desenvolvimento pela Universidade Federal do Paraná - UFPR, Brasil. Pesquisadora da interface entre Comunicação e Meio Ambiente.
Mesmo quando as pessoas têm um contacto sensorial com uma manifestação das alterações climáticas, como o degelo de glaciares, a interpretação desse fenômeno depende de conhecimentos ou concepções mentais que terão adquirido através de algum tipo de discurso. Tais definições têm importantes implicações para o modo como percepcionamos o mundo, bem como para o processo de decisão e acção, e justificam um exame sistemático por parte das ciências sociais e humanas. (CARVALHO, 2011, p.9).

\section{Introdução}

Nas duas últimas décadas, a temática das mudanças climáticas (doravante MCs) tem ganhado espaço no debate público, seja por seus embates políticos e econômicos, seja pelas suas incertezas, intrínsecas ao campo científico, mas que ganham visibilidade devido à ação de negacionistas/céticos. As mídias em geral têm visibilizado as inúmeras questões decorrentes desta temática e, neste contexto, o jornalismo, como arena central de informação, análise e debate, tem relevante papel no esclarecimento da população, especialmente quando se fala de assuntos complexos que ficam restritos a pequenos grupos de especialistas. 
Entende-se 0 jornalismo $0^{1}$ aqui, em primeiro plano, como processo sociocultural amplo que envolve diferentes tipos de atores em seu circuito de produção, texto e recepção. Assume-se, para 0 desenvolvimento deste trabalho ${ }^{2}, 0$ pressuposto de que as notícias legitimadas e divulgadas pelo jornalismo, instituição social com preponderante alcance na sociedade contemporânea, interferem na forma como as pessoas percebem os riscos climáticos e, consequentemente, a maneira com que 0 tema as sensibiliza e as motiva para seu enfrentamento, mesmo levando-se em conta que os efeitos da mídia não são automáticos, direcionados e nem simplesmente incorporados. Diante disso, o problema que move esta investigação é: como melhorar a comunicação de risco e promover 0 envolvimento da sociedade com a governança climática ${ }^{3}$, e de que forma o jornalismo local ${ }^{4}$ fazse presente neste processo? A partir dessa questão geral, indaga-se ainda: qual é a relação entre as percepções de riscos climáticos dos diferentes atores do circuito da notícia e de que modo essa relação poderia colaborar para o enfrentamento das mudanças climáticas?

Dessa maneira, o objetivo geral desta pesquisa é averiguar quais sejam as percepções dos atores envolvidos na produção das notícias sobre MCs (e seus riscos) e como os discursos elaborados por eles são interpretados pelos leitores, buscando captar os pontos de intersecção entre percepção, comunicação e enfrentamento dos riscos. Com outras palavras, procura-se compreender que tipo de relação existe entre os discursos das mudanças climáticas e seus riscos difundidos pelo jornal de maior circulação em Curitiba, capital do Paraná, e as percepções de riscos verificadas nos atores sociais envolvidos em sua produção e recepção, de

Em razão das diferentes perspectivas encontradas nos estudos de interface entre jornalismo e mudanças climáticas, adotamse algumas possibilidades de compreensão do jornalismo com o intuito de alcançar os objetivos dessa investigação de caráter interdisciplinar. São elas: um processo que decorre de construções sociais; um discurso que dissemina certos sentidos e pode amplificar ou atenuar a percepção dos seus leitores; uma prática profissional, que tem rotinas e regras próprias; um ator social capaz de mobilizar instâncias e outros atores para determinadas questões. Ressalta-se que estas concepções, de maneira alguma, são excludentes, convivendo e se complementando de diferentes formas.

Este artigo busca sintetizar a pesquisa de doutorado da autora (LOOSE, 2016a), disponível em: <http://acervodigital.ufpr.br/ handle/1884/43179>. Exemplos das análises das notícias, das respostas das entrevistas realizadas com jornalistas, fontes de informação e leitores, além dos resultados obtidos com a aplicação de questionários de percepção de risco nos atores já citados podem ser encontrados no documento final da pesquisa.

A governança é entendida, neste trabalho, como uma nova forma de tomada de decisão, que é coletiva, envolvendo diferentes sujeitos (FELT e FOLCHER, 2010). Recorda-se que a governança a respeito das MCs é historicamente um procedimento político desenrolado por meio de tratados e reuniões internacionais que envolvem apenas diplomatas e chefes de Estado.

A escala local é relevante para a gestão dos riscos climáticos e os veículos de comunicação que atuam neste âmbito podem colaborar de forma significativa. Pesquisadores da área concordam que a tendência é que se utilizem cidades e municípios como arenas fundamentais de governança. Dessa forma, as MCs tornam-se também problemas urbanos, entrecruzados com outros âmbitos e questões ambientais. Por sua vez, os governos locais precisam ser mais responsáveis e capacitados para mobilizar a população. Este empoderamento local permitiria uma gestão mais eficiente e direta da infraestrutura urbana, dos serviços essenciais e de regulação e controle de ações; contudo, não se pode esperar que os níveis locais resolvam 0 problema sozinhos (MARTINS e FERREIRA, 2011). 
modo a contribuir para uma melhor comunicação de risco e, consequentemente, fomentar ações que motivem o exercício da governança climática no âmbito local.

0 objeto empírico constitui-se no processo de construção e recepção das notícias sobre mudanças climáticas, evidenciando a preferência pelo não afastamento dos estudos de Jornalismo, embora combinem-se, nesta pesquisa, questões atreladas à Psicologia Social (por intermédio da investigação sobre percepção de risco) e temas híbridos do campo ambiental, como a própria compreensão de mudanças climáticas, seus riscos e formas de enfrentá-los. Assim, o trabalho extrapola a pesquisa disciplinar ao não delimitar 0 foco nas estratégias e rotinas do jornalismo, mas entendê-lo como mais um espaço onde há ressignificação e ampla disseminação de sentidos sobre os riscos climáticos. A pesquisa desenvolvese a partir do interesse em compreender os entrelaçamentos que ocorrem em razão da circulação de sentidos sobre riscos climáticos na sociedade, por meio da percepção e da comunicação de riscos.

Posto isso, esta investigação, de caráter predominantemente qualitativo, centra-se na análise das percepções de riscos atrelados às mudanças climáticas dos diferentes atores sociais envolvidos no circuito da notícia do jornal Gazeta do Povo (as fontes jornalísticas consultadas, os elaboradores do discurso - jornalistas - e os receptores das notícias - leitores) e sua relação com as ações de enfrentamento do problema na cidade de Curitiba, evidenciando a perspectiva local da governança climática.

A opção por o circuito da notícia ser estudado a partir do jornal Gazeta do Povo deu-se por três motivos. Primeiro, a imprensa escrita ainda é vista como o espaço do jornalismo diário que desfruta de mais tempo para sua produção e, portanto, pode melhor aprofundar os assuntos abordados, tendo em vista que os meios televisivos, radiofônicos e online tendem a trabalhar com a dinâmica do "ao vivo" ou da publicação em tempo real. Segundo, de acordo com a Associação Nacional de Jornais (ANJ) ${ }^{5}$, a Gazeta do Povo é o maior jornal de circulação paga do Estado do Paraná, estando na $24^{\text {a }}$ posição entre os maiores jornais brasileiros no ranking de 2012, ano do começo da pesquisa. No período da pesquisa, o jornal citado não enfrentava nenhum concorrente na capital do Estado, sendo considerado o jornal de referência dos paranaenses e voltado para 0 público formador de opinião. No site do jornal consta que ele é publicado há mais de 90 anos, revelando-se um produto de tradição, e que foi o primeiro jornal do Paraná e o segundo do Brasil a publicar seu conteúdo na web. E 
terceiro: sendo uma das questões da pesquisa verificar a relação entre 0 discurso jornalístico e as ações de enfrentamento a respeito das mudanças climáticas, a escala local mostrase uma alternativa mais concreta para que os leitores percebam e ajam em prol de uma questão. Conforme sugerem Liu, Vedlitz e Alston (2008), 0 enfoque na escala local, mostrando os efeitos e as possibilidades de enfrentamento que podem ser adotados em cada lugar, rompe com a ideia abstrata e distante que os cidadãos costumam ter sobre as MCs.

Para dar conta do que foi exposto, várias etapas metodológicas precisaram ser adotadas, com técnicas de coleta e análise diferentes, com a finalidade de triangular os resultados no final sob o marco referencial metodológico, chamado por Thompson (1995) de "hermenêutica de profundidade" (HP). Nesse método, a produção, a construção das mensagens e a recepção/ apropriação delas são observadas de modo relacional, elucidando como os diferentes aspectos da comunicação estão atrelados com mais ou menos evidência. Esta proposta teórico-analítica, de caráter híbrido, busca enfatizar os processos do circuito da notícia, à semelhança dos trabalhos realizados por Strelow (2007) e Santi (2009).

Neste artigo não se esmiuçarão as diferentes etapas metodológicas, seja em razão do espaço disponível, seja em razão da complexidade exigida para explicação de cada uma delas. Entretanto, deixa-se claro que, em um primeiro momento, realizou-se um mapeamento das notícias a respeito das mudanças climáticas publicadas na Gazeta do Povo no ano de 2013 e outro acerca das fontes jornalísticas utilizadas para falar de riscos climáticos; nesta etapa foi realizada uma análise de enquadramento $0^{6}$. Examinaramse quais são as percepções de riscos que esses atores sociais (predominantemente cientistas e políticos) tinham, por meio de entrevistas e questionários de percepção de risco. Além disso, foi feito 0 acompanhamento do processo de construção das notícias na redação durante 0 período de divulgação de relatórios e conferência sobre 0 tema, que abarcou também o registro das percepções dos próprios jornalistas sobre MCs e seus riscos.

Posteriormente, investigou-se a recepção de tais notícias e a relação entre elas e a percepção de riscos climáticos de atores que leem as notícias e estão diretamente inseridos em contextos de governança, com familiaridade com a questão ambiental ${ }^{6}$. Ao total, foram feitas e transcritas 62 entrevistas em profundidade com fontes, jornalistas e leitores, além da análise dos questionários de percepção de risco aplicados nesses mesmos atores. As respostas das entrevistas realizadas com os três grupos de 
sujeitos foram transcritas e categorizadas, a partir da Análise de Conteúdo (BARDIN, 2014), de modo específico (questões atreladas ao seu papel no circuito da notícia) e geral (aspectos mais amplos, pertinentes a todos os grupos) ${ }^{7}$.

Com a preocupação de dar conta de todas as etapas do circuito da notícia, delimitou-se temporalmente 0 acompanhamento dos jornalistas na produção de notícias sobre mudanças climáticas entre setembro e novembro de 2013. Esse período compreendeu a divulgação do $1^{0}$ Relatório do Painel Brasileiro de Mudanças Climáticas (PBMC) e do $5^{0}$ Relatório do Intergovernmental Panel on Climate Change (IPCC), além da realização da $19^{\text {a }}$ Conferência das Partes da Convenção-Quadro das Nações Unidas sobre Mudanças Climáticas (COP-19) momentos nos quais a imprensa costuma dar mais ênfase à temática escolhida. A observação participante permitiu um entendimento maior do contexto da produção de tais notícias.

As demais etapas de campo (compostas por realização de entrevistas e aplicação de questionários) foram executadas posteriormente em razão da realização do mapeamento de quem são as fontes jornalísticas consultadas, os jornalistas diretamente envolvidos e os leitores estrategicamente voltados para o gerenciamento dos riscos climáticos em Curitiba, tendo duração de nove meses.
Tal pesquisa, calcada na abordagem

construcionista, volta-se para 0 entendimento das percepções de risco em um processo jornalístico específico: a construção e a recepção de notícias sobre mudanças climáticas no âmbito de Curitiba. Assim, caracteriza-se como um estudo que, a partir de seu detalhamento e aprofundamento, visa ao delineamento de possíveis conexões entre o papel da imprensa local e o desenvolvimento de ações que possam dar conta dos efeitos das mudanças climáticas no próprio município. As análises dos materiais coletados são feitas, predominantemente, a partir de procedimentos qualitativos, apoiadas na Teoria do Enquadramento (no caso das notícias) e na Análise de Conteúdo (entrevistas). 0s dados dos questionários são os únicos analisados de forma quantitativa.

Por fim, a interpretação final dos diferentes momentos do circuito é feita a partir do tríplice enfoque construído por Thompson (1995, p.375), que é composto por três fases: 1) análise sócio-histórica (corresponde à caracterização e definição das condições de produção, circulação e recepção das formas simbólicas analisadas, neste caso, as notícias); 2) análise formal ou discursiva (na qual o interesse está na estrutura dos produtos, da materialidade da forma simbólica) e 3) interpretação/reinterpretação, na qual a "[...] interpretação implica um movimento 
novo de pensamento, ela procede por síntese, por construção criativa de possíveis significados", ou seja, é o esforço de explicar interpretativamente 0 que está representado ou o que é dito.

Na pesquisa desenvolvida, a primeira fase da análise sócio-histórica é trazida seja pela perspectiva contextual da revisão de literatura, ao situar as conjunturas de onde emergem a teoria que sustenta a análise, seja pelo cuidado de reconstruir as condições temporais, institucionais, espaciais, técnicas e de interação no passo a passo da coleta do corpus e de seus desdobramentos analíticos. Já a análise formal ou discursiva constitui a leitura daquilo que as notícias expressam enquanto materialidade do circuito. As notícias são apreendidas como formas simbólicas resultantes de ações situadas e/ou construções por meio das quais algo é dito ou expresso. A terceira e última fase é facilitada pelas análises anteriores, mas transcende a contextualização e a análise formal, revelando-se uma reinterpretação. 0 enfoque tríplice permite que conflitos apareçam e tragam pistas das relações existentes entre cada fase ou etapa. A HP, assim, possibilita verificar os méritos e os limites de cada análise. Nesta investigação essa fase equivale à triangulação final das análises realizadas.

\section{As mudanças do clima compreendidas como riscos contemporâneos}

$05^{0}$ e mais recente relatório divulgado pelo IPCC alerta que o aquecimento do sistema climático é inequívoco e tem forte influência humana. Dentre os efeitos das mudanças climáticas geradas, em grande parte, pelo excesso de emissões de gases de efeito estufa (GEE), o IPCC prevê um planeta com temperaturas médias mais altas, derretimento de geleiras, aumento do nível do mar e, em razão disso, escassez de água e alimentos, extinção de espécies e inundações. As mudanças climáticas hoje são tidas como um dos problemas ambientais mais sérios e em evidência na sociedade.

Ereaut e Segnit (2006) consideram tais mudanças um dos maiores desafios da humanidade neste século, enquanto Wilson (2000) pondera que 0 fenômeno pode ser o maior risco ambiental do nosso tempo. Já Hansen (2011) afirma que o meio ambiente - particular e recentemente apresentado no formato de MCs - tornou-se, nas últimas quatro décadas, uma das preocupações centrais nas arenas públicas e políticas. Porto-Gonçalves (2006) corrobora a ideia do autor quando aponta que o período de globalização neoliberal e de devastação da natureza sem precedentes na história da humanidade levou a sociedade, nos anos 1960/70, a perceber que estava diante de um desafio ambiental em que se inscrevem uma série de questões, como a perda da diversidade e as mudanças do clima.

0 que antes era uma solução para o progresso e 0 crescimento econômico - a exploração dos bens naturais - passou a gerar manifestações que "[...] denunciavam os riscos que a humanidade e 0 planeta passaram a correr em função de um modelo de desenvolvimento [...]" (PORTO- 
GONÇALVES, 2006, p.67), que desconsiderava limites para a intervenção do homem. Dessa forma, a lógica de crescimento econômico fomentada globalmente, calcada no consumo desenfreado de recursos e, consequentemente, na necessidade de exploração contínua, criou problemas que até então não existiam.

Os riscos são incertezas calculáveis que podem ser previstas e amparadas por seguro e compensação monetária. Ainda que o homem seja seu produtor, ele consegue fazer dessa questão outra forma de mercado, apresentando soluções técnicas para isso. Quando Beck (2010) traz a definição de incerteza fabricada, ele ressalta os mesmos elementos trazidos por Grande (2013), ao tratar dos novos tipos de riscos, como o da incalculabilidade, da incontrolabilidade e do alcance global.

Consideram-se aqui os riscos climáticos como riscos ambientais, tendo em vista todas as complexas relações entre sociedade e natureza. Lima (1995) reforça que os riscos ambientais não podem estar ligados apenas às ciências biológicas ou da terra, e sim precisam ser compreendidos como problemas mais amplos, que envolvem o social. Para a autora, a dimensão social dos riscos ambientais justifica-se não somente pelo crescente número de sujeitos expostos - seja pelo crescimento demográfico nas zonas urbanas, seja pela produção de riscos tecnológicos acelerada pela modernidade -, mas pelo "[...] facto de ela implicar decisões grupais acerca do desenvolvimento de tecnologias e da identificação e da gestão dos riscos que lhes estão associados" (LIMA, 1995, p.38). Além disso, há a explicação de que os riscos ambientais são sociais porque eles, normalmente, acentuam as desigualdades sociais, criam mecanismos para a estigmatização social de certas regiões e podem estar na base ou mesmo ser gatilho para a emergência de conflitos sociais.

Destaca-se, por fim, que comunicar os riscos climáticos não é tarefa fácil. Wilson (2000) pontua que as estórias sobre 0 aquecimento global (tomadas como uma parte do todo) são das mais complicadas do nosso tempo - por envolverem ciência probabilística, um rol de leis de diferentes âmbitos, disputas políticas, especulação econômica, entre outras questões. Por ser um assunto complexo, com cruzamento de várias facetas e interesses (científico, político, econômico e social), e dominado pelas fontes científicas, já se tem um quadro com fatores delicados que requerem um bom domínio sobre suas causas e consequências.

Entretanto, para além de um tema ambiental (que pode ter atributos idênticos), as MCs possuem uma escala (global) e um tempo (futuro) de difícil representação e aproximação do público. A proximidade temporal e a geográfica despertam atenção e preocupação; 0 oposto provoca distanciamento do leitor. Moser (2010) sublinha que esse longo intervalo entre causa e efeito é uma das particularidades da comunicação das MCs em relação a outros temas ambientais. 


\section{A percepção de risco e sua relação com 0 enfrentamento}

0 risco está presente de diferentes maneiras no dia a dia das pessoas, e sua aceitação pode variar em razão de motivações, desejos e crenças. A heterogeneidade de preocupações a respeito dos riscos já foi verificada em diversos estudos (LIMA, 2005) e não pode ser simplesmente reduzida à diferença entre técnicos e leigos, questões individuais e sociais, homens e mulheres, brancos e negros etc. As dicotomias entre um fator ou outro não conseguem explicar as múltiplas interações que estão presentes na constituição de cada percepção.

A ideia de risco não é monolítica, muito menos estanque. A avaliação dos riscos pela sociedade envolve uma série de fatores qualitativos e dinâmicos que não costumam ser mensurados ou considerados na avaliação técnica dos riscos.

Desde aspectos contextuais e identitários até mesmo juízos errôneos compõem o rol de ingredientes que formatam a percepção de risco de cada indivíduo.

0 estudo das percepções de risco, ainda que não substitua a avaliação dos peritos e os fatores considerados pelos tomadores de decisão, pode impulsionar processos de gestão de riscos, já que, se forem levados em conta os modos de pensar dos públicos, a aceitabilidade e a resposta aos riscos podem aumentar (RENN, 2004). 0 desenvolvimento das pesquisas de percepção de risco pode auxiliar a diminuir a lacuna entre especialistas e leigos, contribuindo para uma comunicação mais efetiva dos riscos e, também, para 0 engajamento das pessoas nos processos de enfrentamento.

Muitas vezes, o conhecimento sobre riscos e até as formas de enfrentá-los são difundidos pela mídia, o que faz com que esse espaço tornese um meio importante para o surgimento (ou não) da percepção de determinado risco. Mello et al. (2012) destacam que as percepções são influenciadas por fatores socioculturais, incluindo a forma como esses riscos são comunicados pela imprensa, e que compreendê-los tem sido fundamental também para verificar como se dá seu combate. A ideia abraçada pelos autores a partir do pensamento de Ulrich Beck é de que:

[...] o risco deve ser entendido como algo real, que existe objetivamente, e como uma construção social, entendendo que neste processo os fatores socioculturais, as experiências individuais, a ciência, a mídia e a comunicação dos riscos contribuem para a definição, regulação e percepção dos riscos (MELL0 et al., 2012, s/p).

Nesse sentido, enxerga-se o processo de comunicação, como um todo, e o jornalístico, em particular, como espaço de negociação de sentidos, em que os produtores de discursos constroem representações a respeito dos riscos que são interpretados pelos receptores a partir de seu repertório cultural, ou seja, em função de diferentes fatores individuais e sociais que possibilitarão que sua percepção seja mais ou 
menos distante daquilo que foi "projetado" pelos jornalistas. É importante relativizar que os efeitos dos meios não são imediatos, diretos ou perfeitamente correspondentes às intenções dos produtores do discurso. Reconhece-se a potencialidade dos meios de comunicação em amplificar determinadas mensagens, porém, por outro lado, observa-se o receptor como um sujeito ativo, que, ao receber a notícia, ressignifica-a conforme sua ideologia, sua experiência, seu saber e seu interesse.

Veyret (2007) apresenta um modelo associado à construção do risco no qual as mídias posicionamse no centro do processo, enfatizando seu papel preponderante na articulação e mediação de diferentes atores sociais. Diante desse cenário, 0 discurso jornalístico - por seu intuito de relatar o real, ou por ser também uma construção social - está intrincado no processo de dar visibilidade aos riscos. 0 jornalismo tanto se alimenta dos riscos para elaborar seus produtos (textos), como pode promover riscos em função de projeções/ informações desproporcionais. É uma via de mão dupla, em que há uma conformação dos fatos (no caso, riscos) e, ao mesmo tempo, a necessidade de que eles existam (de forma real) para que se tornem notícias.

Nesse contexto, a amplificação social do risco merece ser trazida, considerando 0 alcance dos meios de comunicação. Os mecanismos de informação da amplificação social envolvem experiências diretas e indiretas. Aqueles que tiveram experiências pessoais podem tanto amplificar quanto atenuar os riscos, de acordo com suas condições socioeconômicas e culturais. Não obstante, muitos riscos não são experienciados diretamente, sendo conhecidos por outras pessoas ou pela mídia. Neste último caso, há atributos da informação que contribuem para essa amplificação, como o volume, o grau com que a informação é contestada (se os grupos ou indivíduos acreditam naqueles que questionam as informações), a dramatização e as conotações simbólicas acionadas (KASPERSON et al., 1988). Por exemplo, falar recorrentemente de um dado risco aumenta a percepção de sua gravidade; já a dramatização pode acentuar o potencial catastrófico do desastre, e o conflito entre cientistas pode diminuir a confiança na ciência e, consequentemente, em instituições que se respaldam nela.

Ainda que a amplificação social do risco tenha forte ligação com os meios de comunicação, podendo interferir por meio da recorrência de assuntos, da dramatização, do silenciamento ou da exposição enfática de controvérsias, cada indivíduo, enquanto receptor, também amplifica determinadas informações a partir de suas vivências. Contudo, na maioria dos casos, essa interpretação do acontecimento, que já vem "moldada" pelo enquadramento jornalístico, é aquela que irá gerar as respostas nos indivíduos (de ignorar, tolerar, aceitar ou agir contra o risco). 


\section{Conexões entre as análises: a triangulação dos resultados}

Após as análises em separado dos enquadramentos das notícias sobre MCs da Gazeta do Povo, e das respostas das entrevistas em profundidade e dos questionários de percepção de risco aplicados em jornalistas, fontes de informação e leitores familiarizados com a questão ambiental, que foram categorizadas a partir da Análise de Conteúdo, buscou-se cruzar os resultados. A construção teórico-metodológica a partir de um processo, exposta por meio do circuito da notícia, enfatiza a visão global do jornalismo de modo a convergir com o olhar ambiental, afinado com a complexidade.

Em vez de se mergulhar no detalhamento das partes do circuito, optou-se pela visão do todo, verificando contextos e conflitos de interesses e lógicas, mesmo dentro do recorte específico da construção da notícia. Esta escolha revela mais uma possibilidade de se trabalhar com a perspectiva global da notícia a partir do quadro teórico das percepções de risco e do enfoque na cobertura de um tema específico: as mudanças climáticas. Aqui, mais do que trazer abordagens do campo Ambiental e da Psicologia Social para uma análise comunicacional, entrelaça-se à dinâmica do processo jornalístico uma visão panorâmica, que valoriza o macro.

A opção por uma triangulação ou integração metodológica busca correlacionar os diversos achados da pesquisa, de modo a compreender a processualidade do funcionamento desde a produção até a recepção das notícias sobre MCs. Sob a óptica da interdisciplinaridade, a qual nos diz que é preciso ultrapassar as barreiras disciplinares para compreender os fenômenos híbridos e complexos, que emergem da crise ambiental, faz-se um esforço para transporem-se as dicotomias entre quantitativo e qualitativo, assim como as "purezas" de cada teoria, apostando-se na complementariedade metodológica para implementar e aprimorar a pesquisa empírica.

Thompson (1995) desenvolveu o enfoque tríplice para dar conta da análise das mensagens oriundas dos meios de comunicação de massa, tendo em vista a circularidade dessas formas simbólicas. Assim como a proposta do circuito da notícia, 0 autor propõe análises particulares sobre cada fase (produção, construção e recepção), porém sublinha a necessidade de interpretar e reinterpretar suas inter-relações de forma sistemática. Dessa maneira, mesmo sem a finalidade de interpretar 0 caráter ideológico das mensagens, como fez Thompson (1995), adota-se seu esquema devido à lógica de continuidade e interdependência das etapas para melhor compreensão da apropriação das formas simbólicas.

As inter-relações entre os eixos norteadores e os diferentes momentos do circuito da notícia revelam um quadro complexo no qual as 
percepções de risco se fazem presentes, mas afastadas das responsabilidades e das ações reais dos atores que interpretam as notícias em Curitiba. 0s respondentes da pesquisa demonstram familiaridade com o tema, que pode ser atribuída, em parte, pela visibilidade que a imprensa, de forma geral, tem dado às MCs, em especial, nas últimas décadas, entretanto expressam dificuldade em perceber o risco como algo que possa impactar seu ambiente logo e, por isso, tendem a agir de forma insuficiente para enfrentá-lo.

A respeito das categorias comuns da análise (identificadas em todos os grupos de atores) pode-se dizer que há muito mais concordâncias que divergências entre os grupos investigados. A semelhança e encadeamento entre as respostas majoritárias de cada grupo podem ser interpretadas como um processo de circular influência, no qual algumas ideias acabam sendo reproduzidas do campo científico (por meio dos especialistas que constituem a principal fonte de informação do jornal) para o midiático, através dos jornalistas, e deste para o mundo vivido dos leitores, que esperam mais informações do jornal para enfrentar os riscos climáticos divulgados.

Isso é demonstrado, por exemplo, por meio dos postulados do IPCC, que recebem ampla concordância em todos os grupos, sugerindo que a imprensa auxilia na sustentação do pensamento hegemônico.

Contudo, é preciso relembrar que a recepção é ativa, ou seja, os leitores podem interpretar livremente aquilo que é divulgado pela imprensa, tendo uma apreciação favorável ou contrária, ou ainda ignorando as informações. Também os jornalistas podem não exatamente concordar com as fontes entrevistadas, mas dificilmente terão como não levar em conta essa fala na hora de construir a notícia, especialmente devido às pressões organizacionais e à falta de tempo para consultar novas fontes, que tenham o pensamento mais compatível com 0 seu.

As fontes de informação são aquelas que, teoricamente, teriam mais possibilidade de inserir suas percepções nos discursos jornalísticos, mas, como são entrevistadas a partir de uma determinada pauta, com um recorte predefinido, $\mathrm{e}$ terão seu discurso editado durante a construção da notícia, também não garantem a publicização de seu pensamento tal como disseram. 0 que se depreende dessa constatação é que há muitos mais enredamentos inerentes ao circuito do que as etapas evidenciadas. Não há uma resposta fácil.

Por outro lado, o papel social desempenhado pela mídia na sociedade atual, cercada de riscos, não permite que se excluam as possibilidades desencadeadas em razão de sua credibilidade, visibilidade e alcance. Por meio da análise das notícias do jornal Gazeta do Povo, verificou-se que 0 veículo não polemiza 0 assunto a partir dos dissensos científicos, assumindo, de certa forma, que as MCs estão ocorrendo e têm contribuição humana. Os enquadramentos da responsabilização e do enfrentamento aparecem, 
mas são aqueles relacionados aos riscos, aos possíveis impactos das MCs, os que predominam, especialmente os dos riscos globais.

Ainda que não se possa afirmar o quanto as notícias da Gazeta do Povo sobre MCs tenham contribuído para a construção do que são riscos climáticos e 0 que eles representam no dia a dia dos leitores curitibanos - afinal há muitos outros meios de comunicação que contribuem para isso -, avaliam-se fortes pontos de convergência entre as percepções daqueles que participam do circuito supracitado. De forma majoritária, fontes de informação, jornalistas, textos publicados e leitores expressam concordância com a ocorrência das MCs, com a ausência de links entre os efeitos globais e locais, e com a recorrência de enfoques negativos na imprensa (centrada em riscos). Os sujeitos pesquisados ainda corroboram 0 entendimento de que 0 jornal tem potencial para influenciar seus leitores. As pequenas diferenças que se apresentam entre os grupos ou se manifestam entre os atores de um mesmo grupo não alteram a percepção geral de que as MCs representam um problema com alto grau de gravidade que requer novas abordagens para atrair as pessoas para a ação.

A partir dos resultados, pode-se relacionar a falta de especialização, reconhecida pelos jornalistas entrevistados, à própria vigilância que as fontes demonstram ter quando são procuradas para dar entrevistas, ou seja, o relacionamento da imprensa está balizado, para as fontes, pelo grau de conhecimento que o jornalista mostra ter. A acessibilidade das fontes, além do prestígio e da repercussão do veículo, também se mescla ao reconhecimento profissional que detém o jornalista. Essas evidenciações rebatem nas negociações, descritas na discussão de literatura, nas quais tanto jornalistas como fontes predispõem-se a determinadas situações porque aquilo, em algum sentido, interessa a eles (profissional ou pessoalmente).

Nesta investigação, como a maioria das fontes entrevistadas provém do campo científico (sete das 13 consultadas), emergem reflexos do embate entre a cultura de dois campos sociais com tempos e lógicas muito diferentes. As já conhecidas reclamações de que jornalistas marcam entrevistas em cima da hora e, ao final, publicam apenas uma linha do que a fonte disse não desapareceram, ainda que se tenha notado que as fontes são cientes das rotinas e prazos curtos desse universo. Nas entrevistas com as fontes foi perceptível a compreensão de que seu cuidado e sua atenção com a imprensa pode acarretar notícias mais ou menos contextualizadas, com um número maior ou menor de erros. Mais do que apenas criticar a mídia, muitas fontes destacaram seu papel no resultado do circuito - ainda que lamentem a queda de profissionais especializados e 0 fim de espaços dedicados ao tema.

Nesta mesma linha, os jornalistas não colocam como dificuldade ou obstáculo para a cobertura 0 acesso às fontes. A apropriação de tecnologias 
pelos profissionais das redações, como uso do Skype, permitiu que os jornalistas contatassem pessoas de qualquer lugar do mundo sem sair de Curitiba. Ainda que assumam que a escolha das fontes é bastante subjetiva e, devido ao ritmo frenético da imprensa diária, recorram a pessoas já conhecidas ou que apresentem disposição para falar com jornalistas, o grande problema verificado na cobertura sobre MCs é o excessivo uso de material de agências de notícias (que apresentam enfoques e fontes sobre 0 tema predominantemente internacionais). Esse último aspecto afasta 0 jornal da cobertura local, aproximando-o do tipo de enfoque dado nos jornais hegemônicos.

Na comparação com jornais de circulação nacional, feita pelos próprios sujeitos entrevistados, os leitores veem que 0 conteúdo sobre este tema é o mesmo, que não há produção local. Além da repetição de enfoques negativos, que podem não gerar envolvimento dos cidadãos, os leitores apostam que a visibilidade de boas práticas poderia ser uma forma de tratar 0 assunto de outra forma. Apesar disso, como integrantes de setores aptos a agir pela governança climática e já sensibilizados pela causa ambiental, os leitores entrevistados também demonstram um gap entre sua preocupação com as MCs e suas ações de enfrentamento efetivo. Mesmo práticas mais amplas, associadas à sustentabilidade, não parecem merecer a divulgação, já que há pouca proatividade dos atores no que diz respeito à proposta de pautas para o jornal do qual são leitores.
As desarticulações ratificadas, que afastam os leitores e as fontes de informação paranaenses da produção das notícias, poderiam ser evitadas, caso o jornal entendesse ser um ator importante no quadro da comunicação de riscos e da governança climática local. Como instituição jornalística que detém um papel social, a Gazeta do Povo poderia provocar seus leitores, considerados formadores de opinião pelo próprio jornal, a participar de forma mais ativa na cobertura das temáticas ambientais locais, incluindo aí a relação com as MCs. Essa posição, entretanto, não é assumida e, ao que parece, está sendo menosprezada pela justificativa de cortes financeiros. Logo, o jornal escolhido por ser local acaba atuando da mesma forma que outros sem a mesma especificidade, distanciando o problema do cotidiano dos leitores. Em razão do enxugamento das redações e da diminuição de investimento na cobertura científica-ambiental, é provável que essa prática não ocorra somente no Paraná, mas em diferentes estados e cidades que acabam apenas reproduzindo conteúdos de agências sobre 0 tema.

A página semanal de meio ambiente desapareceu do jornal no começo de 2014, retirando a obrigação de a pauta se manter presente. Embora exista a discussão de que o ideal seria tornar a pauta ambiental transversal (por exemplo, VIVARTA, 2010) e a demarcação de um espaço limitaria a compreensão deste aspecto relacional (afinal, meio ambiente tem a ver com política, com economia, com bem-estar, com saúde etc.), dificilmente a ausência de um espaço tem 
garantido 0 debate de assuntos de forma não fragmentada, como era de se esperar. Se, com a formalização desse espaço, as notícias de MCs já eram publicadas a partir de agências, o que esperar da cobertura com a supressão desse espaço?

Alinhada com a constatação de que os jornalistas locais pouco trabalham para a cobertura climática, verifica-se que o principal jornal de Curitiba não está contribuindo para 0 debate sobre riscos. Como promover um diálogo com a população se os riscos tratados estão lá e não aqui? A abordagem preventiva faz-se ausente e o modo como o tema aparece dificulta a própria construção de uma percepção do risco climático. Os atores compreendem a gravidade e afirmam ter preocupação, mas assinalam os riscos percebidos como possíveis de conviver (devido ao baixo grau de potencial destrutivo) e/ou associados a um tempo futuro.

Sem uma adequada comunicação de risco, as percepções sobre eles se dispersam. Se os cidadãos não se sentem ameaçados ou não percebem 0 quanto podem perder em razão dos efeitos negativos das MCs, não tomarão medidas para combatê-los. Se muitos leitores desta pesquisa, escolhidos em razão de um contato com questões ambientais, não conseguem relacionar suas escolhas diárias com a causa das MCs e/ou pensam que podem mitigar ou prevenir os riscos climáticos apenas com medidas paliativas, o que esperar dos leitores não interessados na área? Como pensar em uma governança climática, que seja participativa, "de baixo para cima" ${ }^{8 ", ~ s e ~ t a i s ~ p e r i g o s ~ n a ̃ o ~ e s t a ̃ o ~ e n t r e l a c ̧ a d o s ~}$ com o cotidiano dos curitibanos?

Esses achados reforçam que, mesmo em um país em que as vulnerabilidades socioambientais são muitas, como o Brasil, o que agrava 0 impacto dos riscos climáticos (PNUD, 2007; PBMC, 2013), a preocupação com o tema não se converte em ação - nem por parte dos jornalistas - , que poderiam ter um posicionamento mais crítico em relação ao meio ambiente, assim como já o fazem contra a corrupção -, nem por parte dos leitores, que não reivindicam ou propõem novos caminhos, mesmo cientes das muitas lacunas existentes e do que isso pode gerar, considerando a influência do jornal. As fontes de informação parecem ser aquelas mais próximas a uma ação condizente com sua preocupação, porém, pensando no circuito, elas desempenham um papel restrito ao ser, geralmente, apenas mais um dos discursos apresentados na notícia.

\section{A proposta da HP permitiu reinterpretar os resultados derivados das análises por etapas, por meio dos procedimentos metodológico instrumentais usados (Análise de Conteúdo} envolvimento dos atores locais atrelados à problemática, oposta à "de cima para baixo" (top-down), no qual as decisões são tomadas de forma hierarquizada. 
e Análise de Enquadramento), e a partir do cruzamento com a análise sócio-histórica, empreendida durante 0 resgate e a discussão dos documentos e literatura da área. Notou-se como o contexto social e cultural de Curitiba é relegado na cobertura das MCs neste jornal, o que deixa manifesta uma ideologia científica hegemônica, calcada nos estudos do IPCC. Em razão de uma percepção de risco climático distante do cotidiano dos leitores, pode-se dizer que a mediação jornalística amplifica os efeitos negativos globais e a discussão sobre acordos internacionais voltada para a responsabilização dos países desenvolvidos, enfatizando a governança "de cima para baixo" e contribuindo para a expansão das decisões executadas do Norte para o Sul.

\section{Considerações finais}

0 problema que moveu a pesquisa buscou saber como o jornalismo local estava ou não presente no processo de comunicação e governança dos riscos climáticos no âmbito de Curitiba. Para tanto, averiguaram-se quais percepções de risco tinham os atores sociais envolvidos no circuito da notícia do principal jornal da cidade, a Gazeta do Povo, assim como de que forma eram construídos os discursos noticiosos. Em razão das análises feitas, pode-se afirmar que as notícias divulgadas pelo jornal diário não repercutem a relação globallocal das MCs, revelando que o caráter local do jornal é seletivo (há cobertura de assuntos locais, mas as MCs, na maioria das vezes, não recebem esse enfoque). Além disso, os próprios atores entrevistados, com algumas exceções, apresentam dificuldade em conectar sintomas locais das MCs no lugar em que residem. Grande parte dos efeitos e riscos das MCs é atrelada à esfera global. Dessa forma, verifica-se que a Gazeta do Povo não atua como um ator a favor da governança, ainda que replique, de forma não sistemática, notícias sobre 0 assunto procedentes de agências de notícias nacionais e internacionais. Sua cobertura sobre o tema enfatiza os riscos climáticos globais, contribuindo para o distanciamento das MCs do cotidiano do seu público.

0 estudo revelou também que há percepções semelhantes sobre os temas abordados nos diferentes grupos de atores (jornalistas, fontes de informação e leitores) e que elas encontram também correspondência nas análises das notícias de 2013, nas quais foram constatados macroenquadramentos científicos, de abrangência global, com ênfase nos enquadramentos de riscos, associados às consequências negativas das MCs. Mesmo que esta não seja uma associação simples, pois há inúmeros outros aspectos culturais, pessoais e contextuais, podem-se delinear parâmetros de entendimento que convergem.

De maneira ampla, pode-se aferir que as percepções de risco se assemelham entre a maioria dos sujeitos e tem rebatimento nos textos publicados pelo jornal; já a comunicação de risco realizada pela Gazeta é considerada como falha pela falta de sistematização, pela superficialidade, ausência de link do global com o local, ênfase 
apenas nos aspectos negativos, dentre outros problemas que evitam a aproximação da população com o tema e, quiçá, diálogo e ação para a gestão dos riscos climáticos. Já a governança climática está distante de ser realizada, seja pelo desconhecimento das ações mitigadoras e adaptativas, seja pela ausência de forte percepção de risco na cidade de Curitiba.

Salienta-se a desarticulação da relação localglobal, amplificada pelo maior jornal de Curitiba, que contribui para uma desmobilização dos leitores, já que estes não são sensibilizados para as causas e consequências das MCs no lugar onde vivem. Tal enquadramento favorece a percepção de não risco real. Afinal, o que devo temer se os efeitos climáticos estão relacionados ao aumento do nivel do mar, e moro a mais de 900 metros de altitude em relação ao mar? Como me afligir com o urso polar se não vejo a conexão de sua extinção com o meu dia a dia? De que maneira posso perceber o aumento médio de temperatura se continuo, na maior parte do tempo, à mercê do clima frio, tipicamente curitibano? Essas são apenas algumas perguntas que servem para exemplificar a falta de comunicação efetiva que vem sido apresentada não apenas na Gazeta, mas em grande parte da imprensa nacional e local, abastecida por agências de notícias internacionais.

Através desta pesquisa foi possível notar que a percepção de risco influencia, em graus diferentes, a ação para o enfrentamento, ou seja, a predisposição à governança "de baixo para cima". Isso não é uma cadeia linear e certeira, mas, sem informação para ajudar na construção de uma percepção de risco climático, seu combate fica ainda mais difícil. E é justamente porque os riscos climáticos são invisíveis e impactam diferentes lugares de forma aleatória, que a representação da mídia se faz relevante para sua percepção.

Em todas aquelas localidades que poderão ser afetadas pelas MCs - a princípio qualquer parte do planeta - e que ainda não perceberam "na pele" seus efeitos, é a imprensa que fará a principal mediação de seu perigo. Nesse sentido, sublinha-se o papel do jornalismo que, pela sua legitimidade e potencial de alcance, poderá difundir esses riscos mesmo para aqueles que, sensorialmente, não o percebem. Este seria um dos contributos sociais da imprensa, pois, por meio de sua visibilidade, estaria permitindo que muitas pessoas tivessem acesso à informação, considerada por muitos pesquisadores como o primeiro passo para 0 exercício da cidadania efetiva.

A relação com o local, as ações de enfrentamento relatadas, assim como a proposta de governança "de baixo para cima" podem ser associadas à prática da cidadania. Quando o sujeito sentese no dever de contribuir com a redução de GEE, por meio de mudanças de hábitos e/ou comportamentos, está exercendo, em alguma medida, sua cidadania planetária. Mas, para tanto, precisa antes reconhecer seus deveres e direitos,

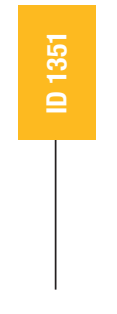


assim como saber as implicações de sua inação. É aqui que a comunicação dos riscos climáticos, particularizada neste trabalho no jornalismo, ganha relevo e merece ser melhor compreendida.

De igual maneira, a pró-atividade por parte da comunidade científica que se dedica aos impactos locais também se revelou pouco presente. Jornalistas entrevistados queixaram-se de dificuldades em acionar as fontes locais, avaliando ser mais fácil contatar cientistas de renome, que contam com assessoria de imprensa e colocam-se à disposição para atender à imprensa. Carvalho (2011) chegou a essas mesmas conclusões em pesquisa semelhante realizada em Portugal, sobre a qual aponta que investimentos sobre a formação dos cientistas na área de divulgação, assim como melhoria de recursos dedicados à comunicação das universidades poderia resultar em um incremento na comunicação das MCs. Tanto neste estudo como no de Carvalho (2011), as instâncias de decisão local mostraram-se "praticamente invisíveis" na mídia, sobressaindo as discussões internacionais, além de se evidenciar a dificuldade de relacionar 0 assunto global com a realidade concreta dos cidadãos.

Outra questão trazida pela pesquisadora portuguesa e com aplicação neste tipo de estudo diz respeito à cautela relacionada à interpretação dos dados e seus possíveis links de causalidade: não é porque os sujeitos consomem muita informação sobre determinado assunto que sua preocupação será maior. 0 consumo de informação e a preocupação podem ter uma relação circular, em que um intensifica o outro: maior preocupação faz com que o consumo de informação sobre isso também aumente e acabe por reforçar a preocupação novamente.

Desse modo, assim como o risco é definido por variáveis contextuais, em que, além do perigo e de sua consciência, a relevância deste no cotidiano do sujeito (que já está cercado por outros riscos) precisa ser considerada, a percepção de risco não depende somente de informação ou manifestação de preocupação. A complexidade inerente a esse processo exige novos detalhamentos, de área diferentes, a fim de apurar e elaborar respostas mais adequadas aos riscos climáticos.

Por fim, menciona-se que foi possível observar de perto as dificuldades entre 0 dizer e 0 fazer, entre a compreensão do assunto e a sua percepção como uma ameaça real na vida das pessoas, entre a intencionalidade de uma ação e sua efetiva concretização. 0 s atores realizam suas escolhas por meio de uma complexa teia de fatores, ideologias, experiências e entendimentos de mundo, fato que torna a tentativa de mobilizálos - seja por meio do jornalismo, seja por ações dos governos - repleta de perplexidades. Dessa forma, concorda-se com Cortese e Natalini (2014, p.113) quando afirmam que "[o] maior desafio está na mudança de comportamento, de hábitos, a necessária revisão de valores". Podese dizer, ainda, que este é o cerne da discussão do enfrentamento das MCs, em suas múltiplas 
escalas, e o ponto mais forte de articulação entre a comunicação de riscos e o jornalismo, investido de seu papel social, e a cobertura das MCs. Mesmo assim, essa continua sendo uma área deixada à margem, uma vez que os estudos relacionados às alterações do clima são majoritariamente de ordem tecnológica e não social (MEIRA, 2009).

\section{Referências}

BECK, Ulrich. Sociedade de risco: rumo a uma outra modernidade. São Paulo: Editora 34, 2010.

BARDIN, Laurence. Análise de conteúdo: edição revista e atualizada. Lisboa: Edições 70, 2014.

CARVALHO, Anabela (Org.). As alterações climáticas, os media e os cidadãos. Coimbra: Grácio, 2011. p.67-102.

CORTESE, Tatiana T. P.; NATALINI, Gilberto.

Importância da participação da sociedade civil organizada e da articulação entre os poderes executivo e legislativo. In: PHILIPPI JR., Arlindo. Mudanças climáticas: do global ao local. Barueri, SP: Manole, 2014. p.99-115.

EREAUT, Gill; SEGNIT, Nat. Warm words: How are we telling the climate story and can we tell it better? London: Institute for Public Policy Research, 2006. Disponível em:

$<$ http://www.ippr.org/assets/media/images/media/files/ publication/2011/05/warm_words_152

9.pdf>. Acesso em: 15 jan. 2015.

FELT, Ulrike; FOCHLER, Maximilian. Machineries for Making Publics: Inscribing and De- Scribing Publics in Public Engagement, Minerva, v.48, n.3, p.219-238, 2010.

GRANDE, Edgar. Os riscos globais e a gestão preventiva. In: INNERARITY, Daniel; SOLANA, Javier (Orgs.). A humanidade ameaçada: a gestão dos riscos globais. Lisboa: Teodolito, 2013. p. 41-66.
HANSEN, Anders. Environment, media and

communication. London: Routledge, 2010.

IPCC. Second Assessment Climate Change 1995.

Disponível em: < https://www.ipcc.ch/pdf/climatechanges-1995/ipcc-2nd-assessment/2nd-assessmenten.pdf > . Acesso em: 15 fev. 2015.

KASPERSON, Roger E.; RENN, Ortwin; SLOVIC, Paul; BROWN, Halina S.; EMEL, Jacque; GOBLE, Robert; KASPERSON, Jeanne X.; RATICK, Samuel. The social amplification of risk: a conceptual framework. Risk Analysis, vol. 8, $\mathrm{n}^{0}$ 2, 1988. p.177 -187.

LIMA, Maria Luísa. Viver com o risco: abordagens da psicologia social ambiental. Inforgeo, v.9-10, p.39-54, 1995.

Percepção de Riscos Ambientais. In: SOCZKA, Luis (Org.). Contextos humanos e psicologia ambiental. Lisboa: Fundação Calouste Gulbenkian, 2005. p.203-245.

LIU, Xinsheng; VEDLITZ, Arnold; ALSTON, Letita. Regional news portrayals of global warming and climate change. Environmental Science \& Policy, v.11, p.379393, 2008.

\section{LO0SE, Eloisa Beling. Riscos climáticos no} circuito da notícia local: percepção, comunicação e governança. Tese de Doutorado. Programa de PósGraduação em Meio Ambiente e Desenvolvimento, Universidade Federal do Paraná, 2016a. 455p.. . A percepção das fontes de informação sobre a cobertura das mudanças climáticas. In: Anais do XIV Encontro Paranaense de Pesquisa em Jornalismo. Curitiba: Departamento de Comunicação da UFPR, $2016 \mathrm{~b}$.

; CARVALHO, Anabela. 0 que pensam os jornalistas sobre seu papel no enfrentamento das mudanças climáticas: as percepções dos profissionais da Gazeta do Povo no Paraná, Brasil. Razón y Palabra, v. 91, p. 1-36, 2015. 
; LIMA, Myrian D. V. L.; CARVALHO, Anabela.

Estudo dos enquadramentos sobre mudanças climáticas no jornal brasileiro Gazeta do Povo. In: PINTO COELHO, Zara; ZAGALO, Nelson. (Org.). Comunicação e Cultura. III Jornadas Doutorais, Ciências da Comunicação e Estudos Culturais. Braga: Centro de Estudos de Comunicação e Sociedade, Universidade do Minho, 2014. p.139-156.

MARTINS, Rafael D'Almeida; FERREIRA, Leila da Costa. Uma revisão crítica sobre cidades e mudança climática: vinho velho em garrafa nova ou um novo paradigma de ação para a governança local? Revista de Administração Pública, Rio de Janeiro, v.45, n.3, p.611-641, 2011.

MELLO, Allan; DI GIULIO, Gabriela; FERREIRA, Lúcia; BATISTELLA, Mateus; CARM0, Roberto. Abordagem quantitativa em estudos sobre percepção de riscos às mudanças climáticas e ambientais: proposta no Litoral Norte de São Paulo. In: ENCONTRO NACIONAL DA ANPPAS, 6, 2012, Belém. Anais... Belém, 2012. Disponível em: < http://www.anppas.org.br/encontro6/ anais/ARQUIVOS/GT11-597-788 20120715130044.pdf>. Acesso em: 20 maio 2015.

\section{MEIRA, Pablo Ángel. Comunicar el Cambio}

Climático: Escenario social y líneas de actuación.

Madrid: Ministerio de Medio Ambiente, Medio Rural y Marino, 2009.

MOSER, Susanne. Communicating climate change: history, challenges, process and future directions.

WIREs Climate Change, v.1, p.31-53, 2010.

PBMC. Contribuição do Grupo de Trabalho 2 ao Primeiro Relatório de Avaliação Nacional do Painel Brasileiro de Mudanças Climáticas. Sumário Executivo do GT2. Rio de Janeiro: PBMC, 2013. Disponível em: < http://www.pbmc.coppe.ufrj. br/documentos/MCTI_PBMC_sumario_executivo_ impactos_vulnerabilidades_e_adaptacao_WEB_3. pdf>. Acesso em: 20 jan. 2014.
PNUD. Informe sobre Desarrollo Humano

2007-2008. La lucha contra el cambio climático: Solidaridad frente a un mundo dividido. New York: Pograma de Naciones Unidas sobre Desarrollo Humano (PNUD), 2007.

PORTO-GONÇALVES, Carlos Walter. A globalização da natureza e a natureza da globalização. Rio de Janeiro: Civilização Brasileira, 2006.

RENN, Ortwin. Perception of risks. Toxicology Letters, v.149, p 405-413, 2004.

SANTI, Vilso Junior Chierentin. As representações no circuito das notícias: 0 movimento dos trabalhadores rurais Sem Terra no jornal Zero Hora. Dissertação (Mestrado) -Universidade Federal de Santa Maria (UFSM), Santa Maria, 2009.

SCHNEIDER, Thais C.; LOOSE, Eloisa Beling. Percepções de leitores sobre mudanças climáticas em Curitiba: investigando relações entre enquadramentos da imprensa e enfrentamento dos riscos. In: Anais do $40^{\circ}$ Congresso Brasileiro de Ciências da Comunicação - INTERCOM. Curitiba: Universidade Positivo, 2017.

SOARES, Murilo César. Representações, jornalismo e a esfera pública democrática. São Paulo: Cultura Acadêmica, 2009.

STRELOW, Aline do Amaral Garcia. Análise Global de Periódicos Jornalísticos (AGPJ): uma proposta metodológica para o estudo do jornalismo impresso. Tese (Doutorado) - PUCRS, Porto Alegre, 2007.

THOMPSON, John B. Ideologia e cultura de moderna: teoria social crítica na era dos meios de comunicação de massa. Petrópolis, RJ: Vozes, 1995.

VEYRET, Yvette. Os riscos: o homem como agressor e vítima do meio ambiente. São Paulo: Contexto, 2007.

VIVARTA, Veet (Coord.). Mudanças climáticas na imprensa brasileira: uma análise comparativa de 50 jornais nos períodos de julho de 2005 a junho de 
2007- julho de 2007 a dezembro de 2008 (Relatório de Pesquisa/2010). Brasília, DF, Agência de Notícias dos Direitos da Infância (Andi), 2010.

WILSON, Kris. Communicating climate change through the media - Predictions, politics and perceptions. In: ALLAN, Stuart; ADAM, Barbara; CARTER, Cynthia (Eds). Environmental Risks and the Media. London: Routledge, 2000. p.201-217. 


\begin{tabular}{|c|c|}
\hline $\begin{array}{l}\text { The climate risks in news } \\
\text { circuit of Gazeta do Povo }\end{array}$ & $\begin{array}{l}\text { Los riesgos climáticos en el circuito } \\
\text { de la noticia de Gazeta do Povo }\end{array}$ \\
\hline $\begin{array}{l}\text { Abstract } \\
\text { This paper is about the relationship between } \\
\text { perception and communication of climate change } \\
\text { and its risks as part of the news circuit of a local } \\
\text { newspaper. More specifically, the study focuses } \\
\text { on Gazeta do Povo, and on the social actors who } \\
\text { participate in its production (information sources } \\
\text { and journalists) and reception (readers of this daily } \\
\text { newspaper). The research includes participant } \\
\text { observation of news production routines, analysis } \\
\text { of risk perceptions of various stakeholders through } \\
\text { questionnaires and interviews, and framing } \\
\text { analysis of news reports, with the ultimate goal } \\
\text { of triangulating findings in light of the approach } \\
\text { proposed by depth hermeneutics. The findings } \\
\text { suggest that the perception of climate risk is removed } \\
\text { from the daily lives of Curitiba readers, and that the } \\
\text { journalistic mediation has amplified the global and } \\
\text { negative effects, as well as a discussion centered on } \\
\text { international agreements, aimed at emphasizing the } \\
\text { responsibility of developed countries. }\end{array}$ & $\begin{array}{l}\text { Resumen } \\
\text { Comprende el estudio de la comunicación y la } \\
\text { percepción sobre el cambio climático y sus riesgos en } \\
\text { el circuito de la noticia de un periódico local. Para tal } \\
\text { fin, la investigación analiza la Gazeta do Povo y los } \\
\text { actores que participaron en su producción (fuentes } \\
\text { de información y periodistas) y recepción (lectores). } \\
\text { Fueron realizadas: observación participante de los } \\
\text { periodistas, investigación de la percepción de riesgo } \\
\text { de los diversos actores sociales y de los encuadres } \\
\text { de noticias con el fin de triangular los resultados con } \\
\text { base en la hermenéutica de profundidad. Entre los } \\
\text { resultados, se constata que la percepción del riesgo } \\
\text { climático está alejada de los lectores, mostrando } \\
\text { que la mediación periodística amplificó los efectos } \\
\text { negativos del fenómeno y la discusión sobre los } \\
\text { acuerdos internacionales. } \\
\text { Palabras-clave } \\
\text { Cambio climático. Circuito de la noticia. } \\
\text { Percepción del riesgo. }\end{array}$ \\
\hline
\end{tabular}

\section{Keywords}

Climate change. News circuit. Risk perception. 


\section{Expediente}

A revista E-Compós é a publicação científica em formato eletrônico da Associação Nacional dos Programas de Pós-Graduação em Comunicação (Compós). Lançada em 2004, tem como principal finalidade difundir a produção acadêmica de pesquisadores da área de Comunicação, inseridos em instituições do Brasil e do exterior.

\section{E-COMPÓS I www.e-compos.org.br I E-ISSN 1808-2599}

Revista da Associação Nacional dos Programas de Pós-Graduação em Comunicação.

Brasília, v.21, n.1, jan./abr. 2018.

A identificação das edições, a partir de 2008, passa a ser volume anual com três números.

Indexada por Latindex I www.latindex.unam.mx

\section{CONSELHO EDITORIAL}

Ada Cristina Machado Silveira, Universidade Federal de Santa Maria, Brasil Alda Cristina Silva da Costa, Universidade Federal do Pará, Brasil Alfredo Luiz Paes de Oliveira Suppia, Universidade Estadual de Campinas, Brasil Ana Regina Barros Rego Leal, Universidade Federal do Piauí, Brasil Ana Carolina Rocha Pessôa Temer, Universidade Federal de Goiás, Brasil André Luiz Martins Lemos, Universidade Federal da Bahia, Brasil Angela Cristina Salgueiro Marques, Universidade Federal de Minas Gerais, Brasil Ângela Freire Prysthon, Universidade Federal de Pernambuco, Brasil Antonio Carlos Hohlfeldt, Pontifícia Universidade Católica do Rio Grande do Sul, Brasil Arthur Ituassu, Pontifícia Universidade Católica do Rio de Janeiro, Brasil

Bruno Campanella, Universidade Federal Fluminense, Brasil

Cláudio Novaes Pinto Coelho, Faculdade Cásper Líbero, Brasil Cárlida Emerim, Universidade Federal de Santa Catarina, Brasil Carlos Eduardo Franciscato, Universidade Federal de Sergipe, Brasil Danilo Rothberg, Universidade Estadual Paulista, Brasil Denise Tavares da Silva, Universidade Federal Fluminense, Brasil Diógenes Lycarião, Universidade Federal do Ceará, Brasil Eduardo Vicente, Universidade de São Paulo, Brasil Eliza Bachega Casadei, Escola Superior de Propaganda e Marketing - SP, Brasil Eneus Trindade, Universidade de São Paulo, Brasil

Erick Felinto de Oliveira, Universidade do Estado do Rio de Janeiro, Brasil Erly Vieira Júnior, Universidade Federal do Espírito Santo, Brasil Francisco de Assis, FIAM-FAAM Centro Universitário, Brasi

Francisco Elinaldo Teixeira, Universidade Estadual de Campinas, Brasil Francisco Gilson R. Pôrto Jr., Universidade Federal do Tocantins, Brasil Frederico de Mello Brandão Tavares, Universidade Federal de Ouro Preto, Brasil Gabriela Reinaldo, Universidade Federal do Ceará, Brasil Gilson Vieira Monteiro, Universidade Federal do Amazonas, Brasil Gustavo Daudt Fischer, Universidade do Vale do Rio dos Sinos, Brasil Itania Maria Mota Gomes, Universidade Federal da Bahia, Brasil Jiani Adriana Bonin, Universidade do Vale do Rio dos Sinos, Brasil José Afonso da Silva Junior, Universidade Federal de Pernambuco, Brasil José Luiz Aidar Prado, Pontifícia Universidade Católica de São Paulo, Brasil Josette Maria Monzani, Universidade Federal de São Carlos, Brasi Juçara Gorski Brittes, Universidade Federal de Ouro Preto, Brasil
Juliana Freire Gutmann, Universidade Federal da Bahia, Brasil Laura Loguercio Cánepa, Universidade Anhembi Morumbi, Brasil Leonel Azevedo de Aguiar, Pontifícia Universidade Católica do Rio de Janeiro, Brasil Letícia Cantarela Matheus, Universidade do Estado do Rio de Janeiro, Brasil Luciana Coutinho Souza, Universidade de Sorocaba, Brasil Maria Ataide Malcher, Universidade Federal do Pará, Brasil Maria Elisabete Antonioli, Escola Superior de Propaganda e Marketing - SP, Brasil Maria das Graças Pinto Coelho, Universidade Federal do Rio Grande do Norte, Brasil Marialva Carlos Barbosa, Universidade Federal do Rio de Janeiro, Brasil Marcel Vieira Barreto Silva, Universidade Federal da Paraíba, Brasil Marcia Tondato, Escola Superior de Propaganda e Marketing, Brasil Marli Santos, Universidade Metodista de São Paulo, Brasil

Márcio Souza Gonçalves, Universidade do Estado do Rio de Janeiro, Brasil Mauricio Mario Monteiro, Universidade Anhembi Morumbi, Brasil Mayka Castellano, Universidade Federal Fluminense, Brasil

Mozahir Salomão Bruck, Pontifícia Universidade Católica de Minas Gerais, Brasil Nísia Martins Rosario, Universidade Federal do Rio Grande do Sul, Brasil Paolo Demuru, Universidade Paulista, Brasil

Paula Melani Rocha, Universidade Estadual de Ponta Grossa, Brasil Potiguara Mendes Silveira Jr, Universidade Federal de Juiz de Fora, Brasil Priscila Ferreira Perazzo, Universidade Municipal de São Caetano do Sul, Brasil Rafael Cardoso Sampaio, Universidade Federal do Paraná, Brasil Rafael Tassi Teixeira, Universidade Tuiuti do Paraná, Brasil Regiane Lucas Garcês, Universidade Federal de Minas Gerais, Brasil Regiane Regina Ribeiro, Universidade Federal do Paraná, Brasil Renata Pitombo Cidreira, Universidade Federal do Recôncavo da Bahia, Brasil Renato Essenfelder, Escola Superior de Propaganda e Marketing, Brasil Roberto Elísio dos Santos, Universidade Municipal de São Caetano do Sul, Brasil Rodolfo Rorato Londero, Universidade Estadual de Londrina, Brasil Roseli Figaro, Universidade de São Paulo, Brasil

Simone Maria Andrade Pereira de Sá, Universidade Federal Fluminense, Brasil Sofia Cavalcanti Zanforlin, Universidade Católica de Brasília, Brasil Sônia Caldas Pessoa, Universidade Federal de Minas Gerais, Brasil Tatiana Oliveira Siciliano, Pontifícia Universidade Católica do Rio de Janeiro, Brasil Thaïs de Mendonça Jorge, Universidade de Brasília, Brasil

Valquiria Michela John, Universidade Federal do Paraná, Brasil

\section{CONSELHO CIENTÍFICO}

Cristiane Freitas Gutfreind, Pontifícia Universidade Católica do Rio Grande do Sul, Brasil I Eduardo Antônio de Jesus, Universidade Federal de Minhas Gerais, Brasil | Eduardo Morettin, Universidade de São Paulo, Brasil I Irene de Araújo Machado, Universidade de São Paulo, Brasil I Miriam de Souza Rossini, Universidade Federal do Rio Grande do Sul, Brasil

\section{COMISSÃO EDITORIAL}

Igor Pinto Sacramento, Universidade Federal do Rio de Janeiro, Brasil I Kelly Cristina de Souza Prudencio, Universidade Federal do Paraná, Brasil I Osmar Gonçalves dos Reis Filho, Universidade Federal do Ceará, Brasil I Rafael Grohmann, Faculdade Cásper Líbero, Brasil I Thaiane Moreira de Oliveira, Universidade Federal Fluminense, Brasil (editores associados)

\section{CONSULTORES AD HOC}

Afonso de Albuquerque, Universidade Federal Fluminense, Brasil I Cláudia Lago, Universidade de São Paulo, Brasil I Cesar Baio Santos, Universidade Federal do Ceará, Brasil I Eduardo Pellanda, Pontifícia Universidade Católica do Rio Grande do Sul, Brasi | Francisco Rüdiger, Pontifícia Universidade Católica do Rio Grande do Sul, Brasil | Karina Woitowicz, Universidade Estadual de Ponta Grossa, Brasil I Luis Mauro Sa Martino, Faculdade Cásper Líbero, Brasil I Norval Baitello Jr, Pontifícia Universidade Católica de São Paulo, Brasil I Pedro Guimarães, Universidade de Campinas, Brasil

\section{EQUIPE TÉCNICA}

ASSISTENTES EDITORIAIS Márcio Zanetti Negrini e Melina Santos | REVISÃO DE TEXTOS Fátima Áli I EDITORAÇÃO ELETRÔNICA Roka Estúdio

COMPÓS I www.compos.org.br

Associação Nacional dos Programas de Pós-Graduação em Comunicação

Presidente

Marco Roxo

Programa de Pós-Graduação em Comunicação - UFF

marcos-roxo@uol.com.br

Vice-Presidente

Isaltina Gomes

Programa de Pós-Graduação em Comunicação - UFPE

isaltina@gmail.com

Secretária-Geral

Gisela Castro

Programa de Pós-Graduação em Comunicação

e Práticas de Consumo - ESPM

castro.gisela@gmail.com

CONTATO I revistaecompos@gmail.com 